\title{
Impact of Atmosphere-Ocean Coupling on the Predictability of Monsoon Intraseasonal Oscillations*
}

\author{
Xiounua Fu \\ IPRC, SOEST, University of Hawaii at Manoa, Honolulu, Hawaii \\ BIN WANG \\ IPRC, and Department of Meteorology, SOEST, University of Hawaii at Manoa, Honolulu, Hawaii \\ DuAne E. WALISER \\ JPL, California Institute of Technology, Pasadena, California \\ LI TAO \\ IPRC, SOEST, University of Hawaii at Manoa, Honolulu, Hawaii
}

(Manuscript received 25 July 2005, in final form 19 April 2006)

\begin{abstract}
The impact of air-sea coupling on the predictability of monsoon intraseasonal oscillations (MISO) has been investigated with an atmosphere-ocean coupled model and its atmospheric component. From a 15-yr coupled control run, 20 MISO events are selected. A series of twin perturbation experiments have been conducted for all the selected events using both the coupled model and the atmosphere-only model. Two complementary measures are used to quantify the MISO predictability: (i) the ratio of signal-to-forecast error and (ii) the spatial anomaly correlation coefficient (ACC).

In the coupled model, the MISO predictability is generally higher over the Indian sector than that over the western Pacific with a maximum of 35 days in the eastern equatorial Indian Ocean. Air-sea coupling significantly improves the predictability in almost the entire Asian-western Pacific region. The mean predictability of the MISO-related rainfall over its active area $\left(10^{\circ} \mathrm{S}-30^{\circ} \mathrm{N}, 60^{\circ}-160^{\circ} \mathrm{E}\right)$ reaches about 24 days in the coupled model and is about 17 days in the atmosphere-only model. This result suggests that including an interactive ocean allows the MISO predictability of an atmosphere-only model to be extended by about a week. The extended predictability is primarily due to the coupled model capturing the two-way interactions between the MISO and underlying sea surface. The MISO forces a coherent intraseasonal SST response in underlying ocean that in return exerts an external control on the future evolutions of the MISO.

The break phase of the MISO is more predictable than the active phase in both the atmosphere-only model and the coupled model as revealed in the observations. Air-sea coupling appears to extend the MISO predictability uniformly regardless of the active or break phases.
\end{abstract}

\section{Introduction}

Intraseasonal variability is a dominant mode of the Asian-western Pacific summer monsoon (Yasunari

\footnotetext{
* School of Ocean and Earth Science and Technology Contribution Number 7004 and International Pacific Research Center Contribution Number 422.

Corresponding author address: Dr. Xiouhua (Joshua) Fu, IPRC, SOEST, University of Hawaii at Manoa, 1680 East West Road, 401 POST Bldg., Honolulu, HI 96822.

E-mail: xfu@hawaii.edu
}

DOI: $10.1175 / \mathrm{JAS} 3830.1$

(C) 2007 American Meteorological Society
1980; Lau and Chan 1986; Wang and Rui 1990; Waliser et al. 2003b). This monsoon intraseasonal oscillation (MISO) constantly regulates the onset (retreat) and active (break) phases of the summer monsoon, and thus strongly influences the weather-sensitive socioeconomic activities (e.g., agriculture) in this area (Webster et al. 1998; Gadgil and Rao 2000). The Asian-western Pacific region is also one of the most vulnerable areas around the world to the impacts of climate-related natural disasters. About $80 \%$ of these natural disasters are caused by extreme hydrometeorological events (e.g., flood, drought, etc.; IFRC 2000). These extreme events are also modulated by intraseasonal variability 
(Goswami and Ajayamohan 2001; Goswami et al. 2003; Jones et al. 2004). If we could provide useful forecast of this intraseasonal variability with lead times of several weeks, it will help the managements of weathersensitive socioeconomic activities and reduce the damage caused by extreme events. In this study, we will explore the predictability of the MISO in a hybrid atmosphere-ocean coupled model and assess the impacts of air-sea coupling on the MISO predictability.

In an intuitive sense, the predictability of a specific atmospheric phenomenon has to be proportional to its own lifetime (Van den Dool and Saha 1990). The recurrent nature of the MISO suggests that, in principle, the useful prediction skill of rainfall associated with the MISO could be exploited by various models for lead times of a month or longer. Some statistical predictive models of the Intraseasonal Oscillation (ISO) have indicated useful skill out to about 15-25-day lead time (Waliser et al. 1999a; Lo and Hendon 2000; Mo 2001; Goswami and Xavier 2003; and Webster and Hoyos 2004). For dynamical models, the pioneer studies of Krishnamurti et al. $(1990,1992)$ suggested that the useful forecast skill of the flow fields associated with the MISO could reach 20-30 days for a few special events. From the historical view in the progress of weather forecast (Kalnay 2003), we learned that both statistical and dynamical models significantly contribute to the improvement of forecast. Dynamical models, on the other hand, show greater potential to be improved and offer more opportunities to advance our understandings of the related physical processes.

Waliser et al. (2003b,c) first systematically examined the potential predictability of the ISO [both the MISO in boreal summer and Madden-Julian oscillation (MJO) in boreal winter] using the National Aeronautics and Space Administration (NASA) Goddard Laboratory for Atmospheres (GLA) AGCM with a series of twin-perturbation experiments. An objective signal-toerror measure was used to quantify the predictability of the ISO. They concluded that the limit of predictability for the model's ISO extends out to about 25 days for $200-\mathrm{hPa}$ velocity potential and to about 15 days for rainfall. Recently, Liess et al. (2005) found that the upper limit of rainfall predictability associated with the MISO in the ECHAM5 AGCM could reach one month in some specific regions over the Asian-western Pacific domain. With the National Centers for Environmental Prediction (NCEP) forecast model, Reichler and Roads (2005) found that the predictability of the 200-hPa velocity potential in the Tropics reaches about 4 weeks, but almost no predictability for model rainfall when same measure is used. These studies tend to suggest that the potential predictability of some dynamic fields associated with the ISO in the state-of-the-art AGCMs could reach about one month. However, the predictability of the ISO-related rainfall is much shorter and varies considerably among different models.

Further, in an operational setting, the potential predictability of dynamical models will be shortened by the errors existing in the initial and boundary conditions and the weaknesses of models in representing the structures, intensity, and propagation of the ISO (Chen and Alpert 1990; Lau and Chang 1992; Hendon et al. 2000; Seo et al. 2005). The predictive skill of the boreal winter ISO in an old version (Hendon et al. 2000; Jones et al. 2000) and a latest version (Seo et al. 2005) of the NCEP forecast model is only about 7-10 days for the related dynamic fields when SSTs are fixed on climatology. The relative short forecast skill is largely related to the model's deficiencies in maintaining the large-scale circulations and representing the propagations of the ISO. Apparently, in order to improve the prediction of the ISO in dynamic models, we need to further improve the model representations of the ISO and explore better ways to set up the initial and boundary conditions.

On intraseasonal time scale, in addition to the initial conditions (Krishnamurti et al. 1992), boundary conditions (e.g., the intraseasonally varying SSTs) probably also play very important role on the ISO prediction (Reichler and Roads 2005). However, in an operational setting, the intraseasonal SST fluctuations are not known a priori. Thus, an atmosphere-ocean coupled model is needed to generate an interactive SST for the forecast system. In fact, most previous studies have supported the notion that air-sea coupling can significantly improve the simulation of tropical ISO compared to atmosphere-only models (Flatau et al. 1997; Wang and Xie 1998; Waliser et al. 1999b; Kemball-Cook et al. 2002; Fu et al. 2003; Inness and Slingo 2003; Matthews 2004; among others). The exception of Hendon (2000) is largely attributed to errors in the model's mean state and an associated failure of the model to simulate a correct relationship between ISO-driven surface latent heat flux and rainfall anomalies. Based on the aforementioned findings, we will address the following question in this study: Could the predictability of tropical ISO in an atmosphere-only model be improved by including active air-sea coupling? We expect a positive answer to this question for two reasons. First, by improving the simulation of the basic ISO characteristics, namely those related to spatial structure and evolution, intensity, propagation speed, and seasonality. Second, the intraseasonal SST fluctuations lead the ISO-related convection by about 10 days in both the coupled model (Fu et al. 2003; Zheng et al. 2004) and the observations 
(Arakawa and Kitoh 2004); this relationship is not present in the atmosphere-only model. In other words, the intraseasonal SST fluctuations in the coupled system may provide a memory to extend the predictability of the ISO. This hypothesis will be examined in the following study.

In section 2, we introduce the hybrid atmosphereocean coupled model and briefly validate the simulated MISO with the satellite observations from the Tropical Rainfall Measuring Mission (TRMM) Microwave Imager (TMI). (TMI data are acquired from Remote Sensing Systems available online at http://www.ssmi. com/tmi/tmi_browse.html.)

Section 3 describes the framework to conduct the ensemble experiments and the methods to quantify the predictability of the MISO, which basically follow those used in Waliser et al. $(2003 \mathrm{~b}, \mathrm{c})$. Section 4 presents the MISO predictability in the coupled model and the portion contributed by air-sea coupling. Section 5 examines the dependence of the MISO predictability on the active and break phases. Section 6 discusses some issues raised from current study. The last section summaries our major findings and identify several future research directions.

\section{Model}

\section{a. Model description}

The hybrid coupled atmosphere-ocean model combines the ECHAM4 atmospheric general circulation model (AGCM; Roeckner et al. 1996) and an intermediate ocean model (Wang et al. 1995; Fu and Wang 2001). The details of this hybrid coupled model and its simulations of the tropical Asian-Pacific climate can be found in Fu and Wang (2004b) and X. Fu et al. (2006, unpublished manuscript; available at http:/www.soest. hawaii.edu/ xfu/HcGCM.pdf). For the convenience of readers, a brief description of the coupled model is given in the following.

The atmospheric model is a T30 version of ECHAM4 with horizontal resolution of about $3.75^{\circ}$ and 19 vertical levels extending from the surface to $10 \mathrm{hPa}$. Its land surface scheme is a modified bucket model with improved parameterization of rainfall runoff (Dumenil and Todini 1992). The cumulus parameterization is a modified version of the mass flux scheme developed by Tiedtke (1989). The improved version replaces the original moisture-convergence closure scheme with convective available potential energy (CAPE) closure (Nordeng 1994). The radiation scheme is a modified version of the European Centre for Medium-Range Weather Forecasts (ECMWF) scheme. Two- and six- band intervals are used in the solar and terrestrial part of the spectrum, respectively.

The ocean component of this hybrid-coupled model is a tropical upper ocean model with intermediate complexity. It was originally developed by Wang et al. (1995) and later improved by Fu and Wang (2001). The ocean model comprises a mixed layer, in which the temperature and velocity are vertically uniform, and a thermocline layer in which temperature decreases linearly from the mixed-layer base to the thermocline base. Both layers have variable depths. The deep ocean beneath the thermocline base is motionless with a constant reference temperature. This ocean model combines the mixed-layer physics of Gaspar (1988) and the upper ocean dynamics of McCreary and Yu (1992). It reasonably simulates the annual cycles of sea surface temperature, upper ocean currents, and mixed layer depth in the tropical Pacific (Fu and Wang 2001).

The ECHAM4 AGCM was coupled with the intermediate ocean model in the tropical Indian and Pacific Oceans $\left(30^{\circ} \mathrm{S}-30^{\circ} \mathrm{N}\right)$ without heat flux correction [except that the SSTs in the north-south open boundaries have been relaxed to the observed climatologic monthly mean as in Fu and Wang (2001)]. Outside the coupling region, the underlying sea surface temperature is specified as the climatological monthly mean SST from the Second Atmospheric Model Intercomparison Project (AMIP II) experiment (Taylor et al. 2000). In the tropical Indian and Pacific Oceans, atmospheric component exchanges information with ocean component once per day. The atmosphere provides daily mean surface winds and heat fluxes to the ocean model. The latter provides daily mean SST back to the former. Prior to carrying out the forecast experiments, a 21-yr coupled integration was conducted. The output from the last $15-y r$ of integration will be referred to as the control run.

\section{b. The MISO simulated in the coupled model}

This hybrid coupled atmosphere-ocean model reasonably simulates the climatology and interannual variability in the tropical Asian-Pacific sector (X. Fu et al. 2006, unpublished manuscript). It also shows reasonable skill to reproduce the major observational characteristics of the MISO in the Asian-western Pacific sector, such as the location of major active centers, seasonal variations in amplitude, dominant periods and spatial-temporal evolutions. Those characteristics have been validated in our previous studies (Fu et al. 2003; Fu and Wang 2004a,b; X. Fu et al. 2006, unpublished manuscript).

Figure 1 further compares the regressed rainfall and SST fluctuations associated with the MISO in the TMI 
TMI
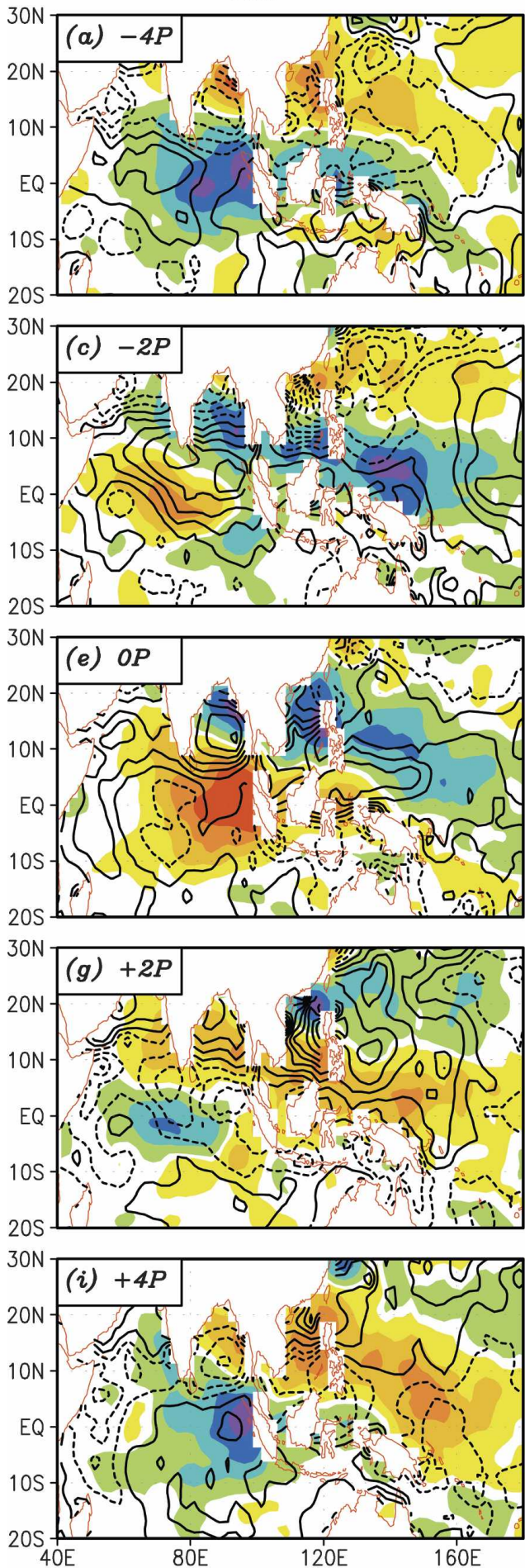

Coupled Model
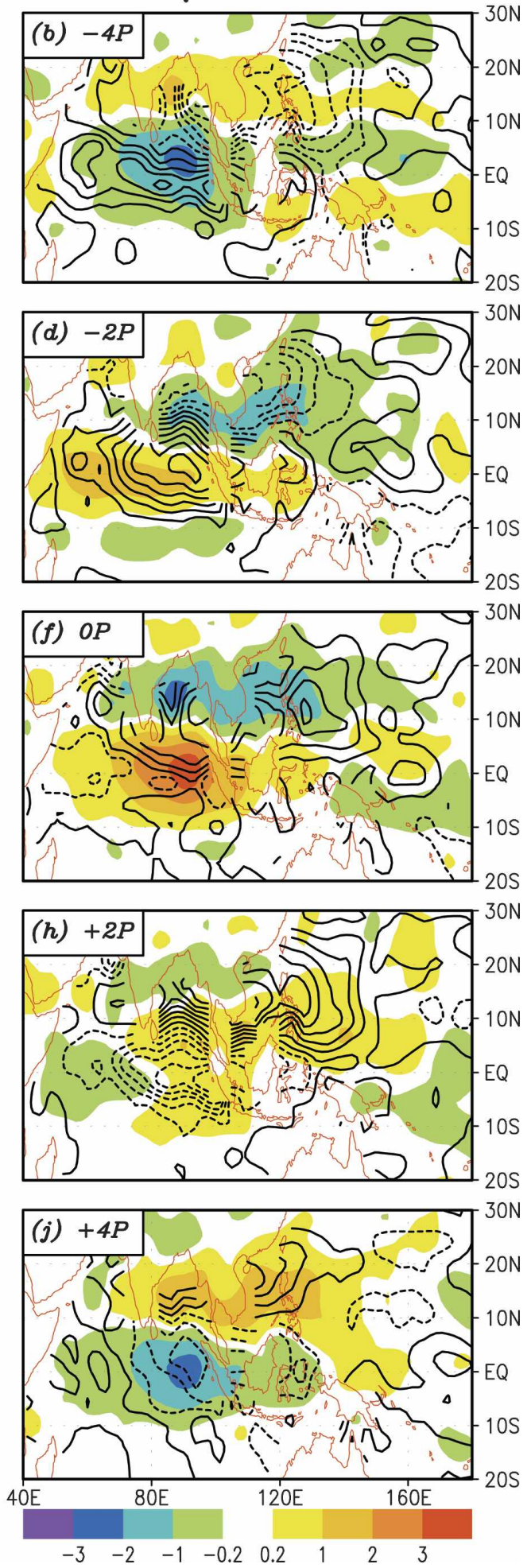

FIG. 1. The regressed space-time evolutions of intraseasonal SST (contour interval: $0.02^{\circ} \mathrm{C}$ ) and rainfall (shaded; $\mathrm{mm} \mathrm{day}^{-1}$ ) anomalies associated with the MISO from TMI observations and the coupled model with respect to the rainfall time series averaged in the eastern Indian Ocean $\left(5^{\circ} \mathrm{S}-5^{\circ} \mathrm{N}, 80^{\circ}-100^{\circ} \mathrm{E}\right)$ at (a), (b) -4 ; (c), (d) -2 ; (e), (f) 0; (g), (h) +2; and (i), (j) +4 pentads. 
observations (1998-2003) and the coupled model. The filtered rainfall (only 20-90-day variability is retained) over the eastern equatorial Indian Ocean (EIO; $5^{\circ} \mathrm{S}-$ $5^{\circ} \mathrm{N}, 80^{\circ}-100^{\circ} \mathrm{E}$ ) is used as the reference time series for the regression. At 4 pentads before the rainfall peaks in the EIO (Figs. 1a,b), the dry phase prevails in the entire equatorial Indian Ocean and Maritime Continent with a rainy belt around $15^{\circ} \mathrm{N}$ in both the observations and the coupled model. The positive SST anomalies start to form in the equatorial Indian Ocean associated with reduced convection. The negative SST anomalies, owing to enhanced convection, appear in the northern side of the dry zone. Both the internal dynamics (Jiang et al. 2004) and SST anomalies (Fu et al. 2003) play a role in leading to the disturbances moving northeastward (Figs. 1c,d). When the dry zones move off the equator, the MISO-related convection initiates and intensifies in the equatorial Indian Ocean (Fig. 1c-f). The positive SST anomalies start to form in the northeast side of the wet zone and help the convection moving northeastward (Figs. 1g-j). The simulated rain-belt in the northern Indian Ocean (Fig. 1h) is weaker and moves slower than the observed (Fig. 1g).

Overall, the patterns of rainfall and SST anomalies between the observations and the simulations are similar except that the magnitude of rainfall and SST perturbations in the simulation is slightly smaller than their counterparts in the TMI observations and the simulated enhanced/suppressed rainfall belts tend to be more zonally oriented. The simulated spatial patterns in the western Pacific are also not as coherent as in the observations. On the other hand, this hybrid-coupled model produces robust intraseasonal variability in the equatorial Indian Ocean (see also Figs. 7a-e), where almost all atmosphere-only GCMs participating in the Climate Variability and Predictability (CLIVAR)/ Asian-Australian monsoon intercomparison project considerably underestimate the intraseasonal variability (Waliser et al. 2003a).

\section{Methods}

To quantify the predictability of the MISO in a model, a large ensemble of forecasts is needed. There are two methods that have been used to generate the ensemble forecasts: 1) conducting a small number of perturbation experiments for many MISO events (Waliser et al. 2003b; Reichler and Roads 2005), and 2) performing a large number of ensembles for a few events (Tracton and Kalnay 1993; Liess et al. 2005). Because our major purpose is to assess the differences of the predictability between a coupled system and an atmosphere-only system, including many MISO events probably better justifies the differences. Therefore, the twin-perturbation method (Lorenz 1982; Waliser et al. 2003b) for many MISO events has been used in this study to generate a pool of ensemble forecasts.

\section{a. Experimental designs}

Figure 2 shows the 15-yr filtered rainfall time series averaged in the EIO during boreal summer (MayOctober). Two criteria have been used to select the target MISO events: first, the magnitude of rainfall fluctuations should be larger than $4 \mathrm{~mm} \mathrm{day}^{-1}$; second, the candidate event should exhibit four distinct phases of evolution (i.e., break, break-to-active, active, and active-to-break). Based on these criteria, 20 MISO events were identified from the 15-yr control run. Except for year 16 (see Fig. 2), all other years have at least one event being selected.

For the selected 20 MISO events, a series of forecasts were conducted, with two perturbed forecasts started from each event's four individual phases (the number of total forecasts, $N=2 \times 4 \times 20=160)$. The initial conditions are perturbed by adding day-to-day rootmean-square (RMS) differences of four prognostic variables $(u, v, T, q)$ onto the original initial conditions as in Waliser et al. (2003b). The details to produce these perturbed initial conditions can be found in Waliser's paper. Started from these perturbed initial conditions, the twin forecasts were conducted with the coupled model and the atmosphere-only model. In the coupled forecasts, the coupled system generates its own SST as boundary condition to force the atmosphere. In the atmosphere-only system, the smoothed SST from the coupled control run has been used as boundary forcing. In this case, the smoothing means that the intraseasonal variability (20-90 days) in the SST of the coupled control run was removed to exclude the intraseasonal information from the underlying boundary. In this way, the interannual variations in the SST remain the same between the coupled and uncoupled forecasts. The differences of the MISO predictability between these two systems are then attributed to the impact of air-sea coupling.

As in Waliser et al. (2003b), all perturbed forecasts have been integrated for 90 days. To extract the intraseasonal variability and distinguish its predictability from weather fluctuations, 120-day output from the control run before the initial condition has been concatenated to the 90-day forecast. Then bandpass filtering has been used to the 210-day time series to extract the 20-90-day intraseasonal signals.

\section{b. Measures of MISO predictability}

Two complementary measures (Hollingsworth et al. 1980) are used to quantify the MISO rainfall predict- 


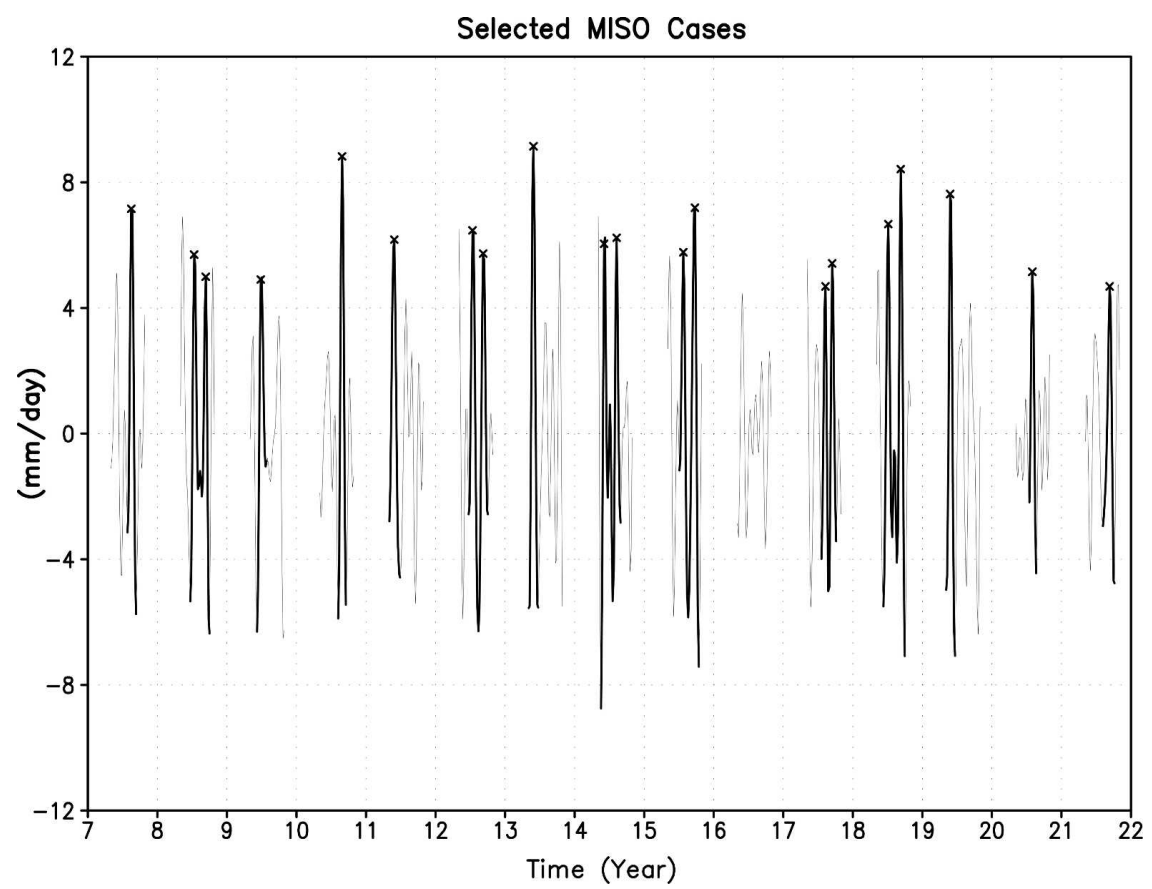

FIG. 2. The filtered rainfall time series averaged in the eastern Indian Ocean $\left(5^{\circ} \mathrm{S}-5^{\circ} \mathrm{N}\right.$, $80^{\circ}-100^{\circ} \mathrm{E}$ ) from the last 15 -yr coupled control run. The $20 \mathrm{MISO}$ events selected to assess the model predictability are highlighted.

ability for both the coupled system and the atmosphereonly system. One is the ratio of signal-to-forecast error (Waliser et al. 2003b). The other is the anomaly correlation coefficient (Miyakoda et al. 1972; Hollingsworth et al. 1980).

In the first measure, the signal of a given MISO event is defined as the variance of intraseasonal variability of the coupled control run averaged within a sliding window (with a time span of 50 days) that is large enough to encompass an MISO event (Goswami and Xavier 2003; Waliser et al. 2003b). The forecast error of a given event is defined as the variance of the difference between the perturbed forecast and the coupled control case. The MISO predictability in days is defined as the time when the signal and forecast error intersect. Because both the signal and forecast error are calculated at individual grids, this method gives a geographic distribution of the predictability. On the other hand, the ACC measures the pattern similarity of two fields over a given domain. Because the MISO exhibits coherent spatial-temporal evolutions in the Asian-western Pacific region (Fig. 1), the ACC gives a measure complementary to the pointwise signal-to-forecast error. The predictability is then defined as the time when the ACC drops to a given correlation value. To get a reasonable ACC criterion, the rainfall spatial patterns of a selected MISO event and its forecast at different lead times are compared in Fig. 3. The pattern correlation coefficients have been calculated between the targets and forecasts. For this particular case, even at day 30 the forecast (Fig. 3j) still looks skillful compared to the target (Fig. 3i). The corresponding pattern correlation coefficient is about 0.43 at this time. Based on this result and previous study (Reichler and Roads 2005), the ACC criterion is set to 0.5 in the following analysis.

\section{Impact of air-sea coupling on the MISO predictability}

To assess the impact of air-sea coupling on the MISO predictability, a series of forecasts have been conducted for all selected events started from four reference phases using both the coupled model and the atmosphere-only model. Starting the forecasts from different MISO phases provide an opportunity to estimate the dependence of predictability on initial atmospheric states. The four reference phases are determined from the daily time series of the filtered rainfall averaged in the EIO. Phase 1 (break phase) is identified as the day when the rainfall anomaly in the EIO reaches a minimum. Phase 2 (break-to-active) corresponds to the day when the rainfall anomaly crosses zero from negative to positive. Phase 3 is the peak active phase and phase 4 represents the transition day from active to break phase. Figure 4 shows the composite spatial patterns of rainfall and SST anomalies associated with different phases from the control run averaged for all selected 
Target_Event
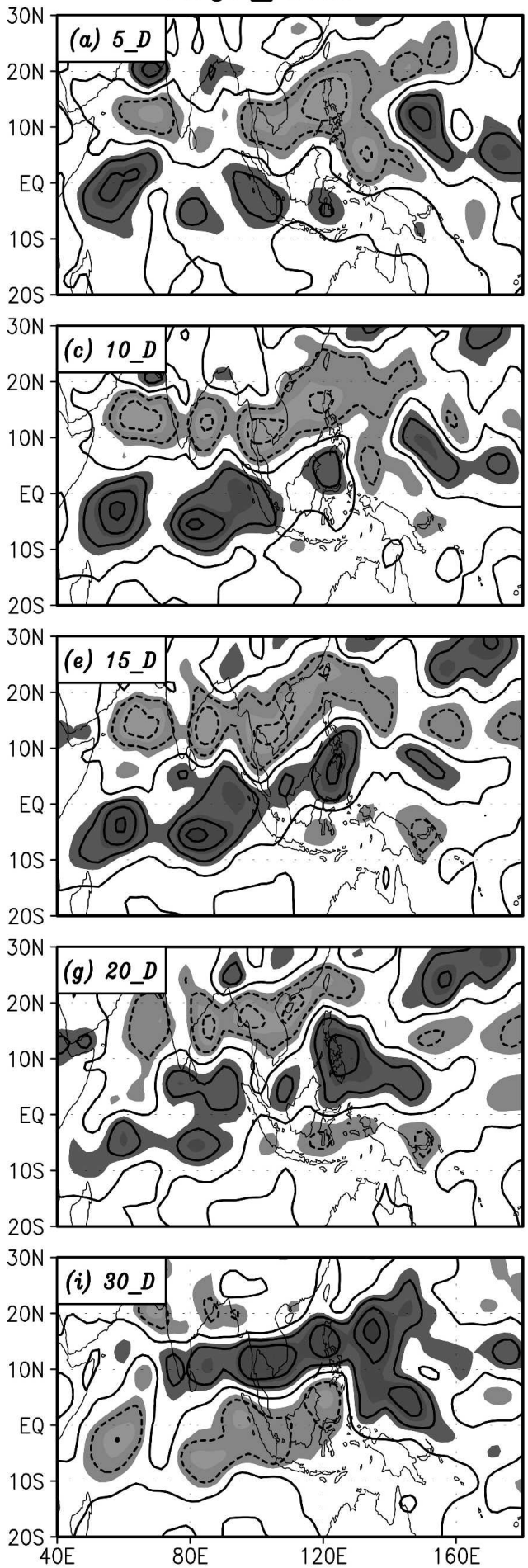

Forecast
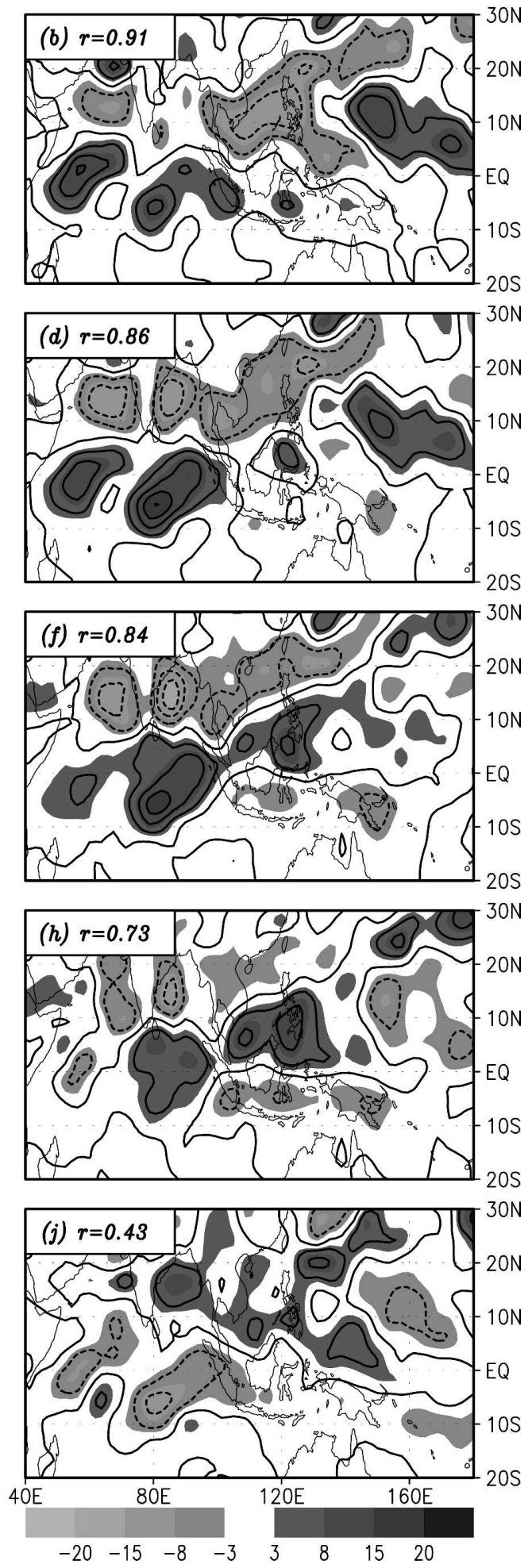

FIG. 3. The space-time evolutions of filtered rainfall anomalies (20-90 days) for one MISO event selected from (left) the coupled control run and (right) one coupled forecast. The forecast days are shown in the small boxes of the left panels. The correlation coefficients between the left and right panels are given in the small boxes of the right panels. The contour interval is $5 \mathrm{~mm} \mathrm{day}^{-1}$. 

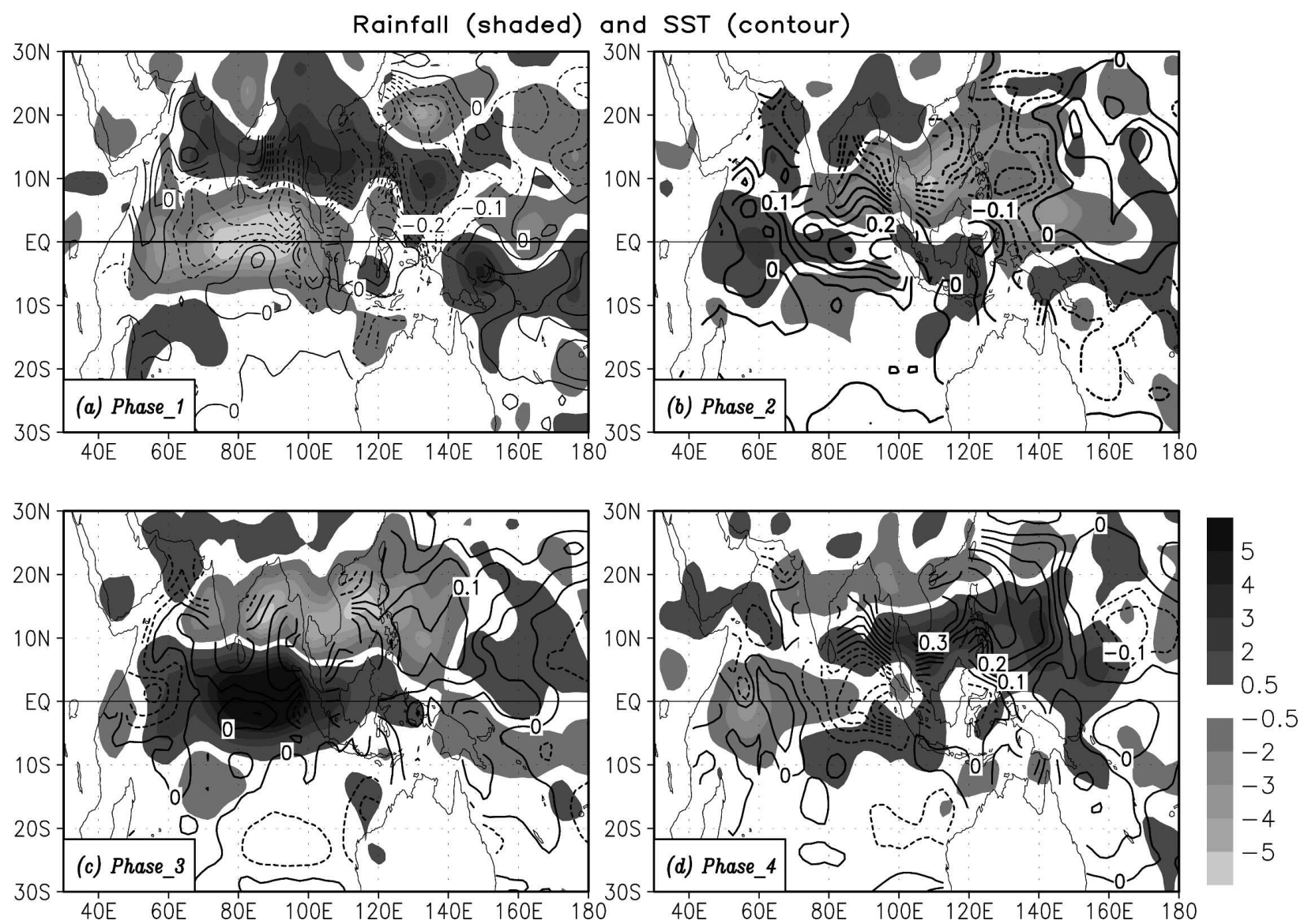

FIG. 4. Composite rainfall (shaded; $\mathrm{mm} \mathrm{day}^{-1}$ ) and SST (contour interval: $0.05^{\circ} \mathrm{C}$ ) anomalies for all selected MISO events at (a) phase 1 , (b) phase 2, (c) phase 3, and (d) phase 4.

events. Generally speaking, the composite phase $1,2,3$, and 4 correspond to the $-4,-2,0$, and +2 pentads in the regression analysis, respectively (Fig. 1).

\section{a. MISO predictability measured by the signal-to-error ratio}

The signals and forecast errors of all the selected MISO events at their associated four phases have been calculated at individual grid points. Figure 5 shows the signals and forecast errors averaged over the EIO as function of forecast days at each phase in both the coupled model and the atmosphere-only model. For all phases, the signals don't change much as forecast time increases, but the forecast errors grow steadily. In the coupled system, the MISO predictability, defined as the time when forecast error intersects with the signal, is about 29, 35, 33, and 22 days, respectively, for phase 1 to 4 (Figs. $5 \mathrm{a}-\mathrm{d}$ ). ${ }^{1}$ In the atmosphere-only model, the

\footnotetext{
${ }^{1}$ The nonzero errors before the start of forecasts are due to the use of filtering.
}

forecast errors grow considerably faster than their counterparts in the coupled system. The corresponding predictability in the atmosphere-only model is about $17,17,26$, and 18 days from phase 1 to 4 . In general, the predictability of the coupled model is systematically higher than that of the atmosphere-only model. In this particular region, the forecasts started from phase 3 (active) have longer predictability than those started from phase 1 (break). This predictability difference between two specific phases is more outstanding in the atmosphere-only model than that in the coupled model. We will come back to this point later.

To get an overall view of the MISO predictability in its most active region, the signals and errors of all forecasts for four phases have been averaged over the tropical Asian-western Pacific domain (AWP; $10^{\circ} \mathrm{S}-30^{\circ} \mathrm{N}$, $60^{\circ}-160^{\circ} \mathrm{E}$ ). The averaged MISO predictability of all four phases in the AWP domain is about 24 days for the coupled system and 17 days for the atmosphere-only system (Fig. 6). This difference suggests that the air-sea coupling acts to extend the MISO predictability by about a week in the AWP region. This result somewhat 

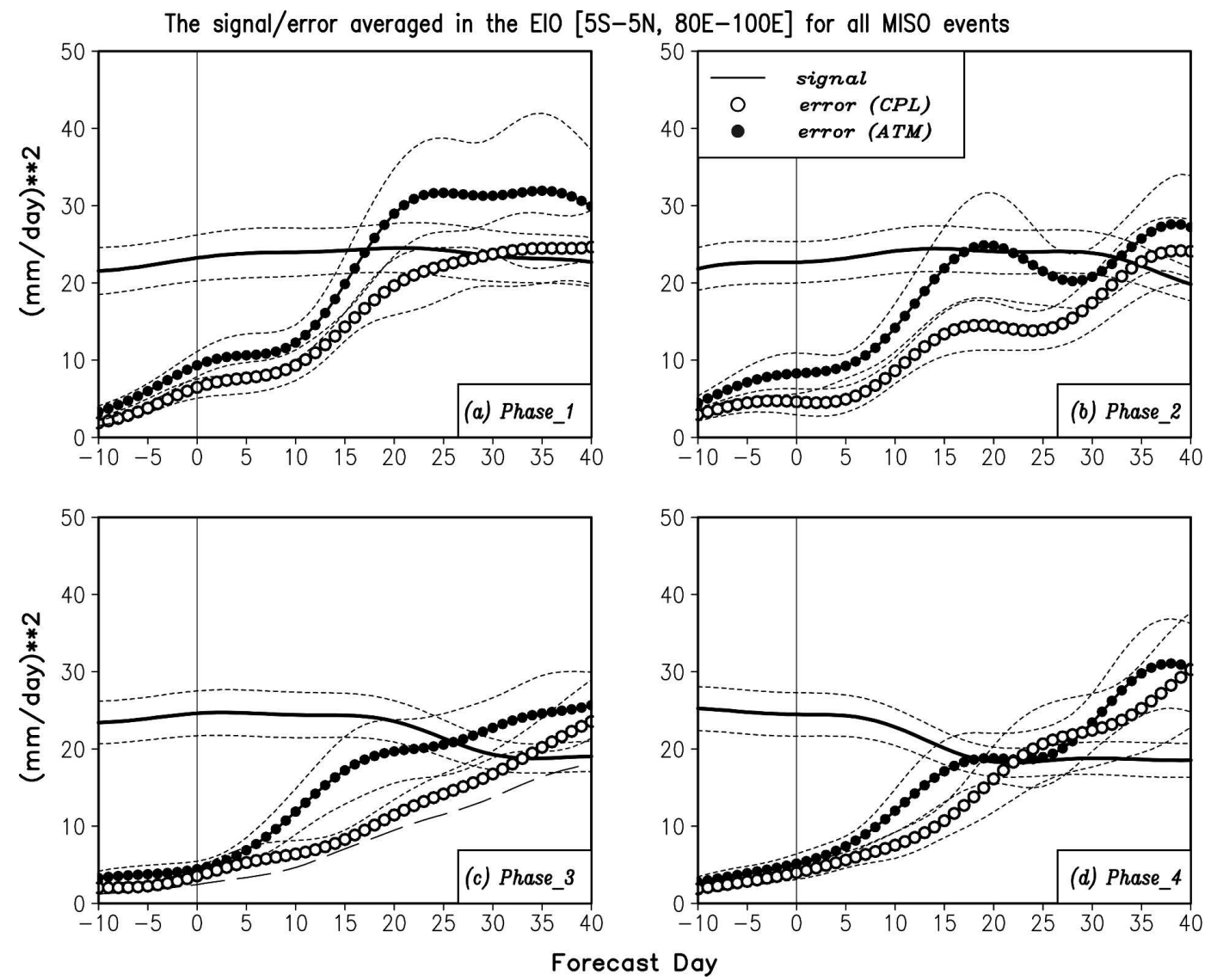

FIG. 5. The rainfall signals and forecast errors $\left(\mathrm{mm} \mathrm{day}^{-1}\right)^{2}$ as function of lead time averaged in the eastern Indian Ocean $\left(5^{\circ} \mathrm{S}-5^{\circ} \mathrm{N}, 80^{\circ}-100^{\circ} \mathrm{E}\right)$ for all selected MISO events when the forecasts start from (a) phase 1 , (b) phase 2 , (c) phase 3, and (d) phase 4 using the atmosphere-ocean coupled model (CPL) and the atmosphere-only model (ATM). The thin dotted lines show the 95\% confidence limits for the signals and errors with a Student's $t$ test.

confirms previous hypothesis (Waliser et al. 2003b; Fu and Wang 2004b): "if the interaction between the convection and large-scale circulations (purely internal atmospheric dynamics) can give a useful MISO prediction of about 15 days, a coupled system might extend the predictability to about one month."

Figure 7 presents the geographic distributions of signals and errors averaged for all coupled forecasts in the Asian-western Pacific region at lead times of 5, 10, 15, 20 , and 30 days. At all lead times, the spatial pattern and magnitude of the MISO signals are almost the same (Figs. 7a-e) although the amplitude in the Bay of Bengal shows slightly decaying as forecast time increases. The model reasonably captures the major observed MISO action centers in this domain [Corresponding observations can be found in Fig. 2 of Waliser et al. (2003a) and Fu and Wang (2004b)]. Strong variability is reproduced in the Bay of Bengal, eastern Arabian Sea, equatorial India Ocean, South China Sea, and western
North Pacific (WNP). However, the simulation in the western Pacific is not as coherent as in the observations probably due to the systematic error in the model mean state. The model simulated a zonal rainbelt around $15^{\circ} \mathrm{N}$ (figure not shown) in boreal summer over the WNP, contrast to the observed northwest-southeasttilted rainbelt. The forecast errors grow gradually as the lead-time increases (Figs. 7f-j). At forecast day 5, only a few spots corresponding to the MISO action centers have error variance larger than $10\left(\mathrm{~mm} \mathrm{day}^{-1}\right)$. When time goes on, the errors tend to grow faster in the western Pacific than in the Indian Ocean. This also seems true in the NASA GLA model (Fig. 11 of Waliser et al. 2003b). The faster error growth in the western Pacific may be related to the rapid development of synoptic disturbances, which tend to grow fast in this region owing to the peculiar basic states (Lau and Lau 1990; Tam and Li 2006). At forecast day 20 (Figs. 7d,i), the magnitude of errors in the western Pacific becomes similar 


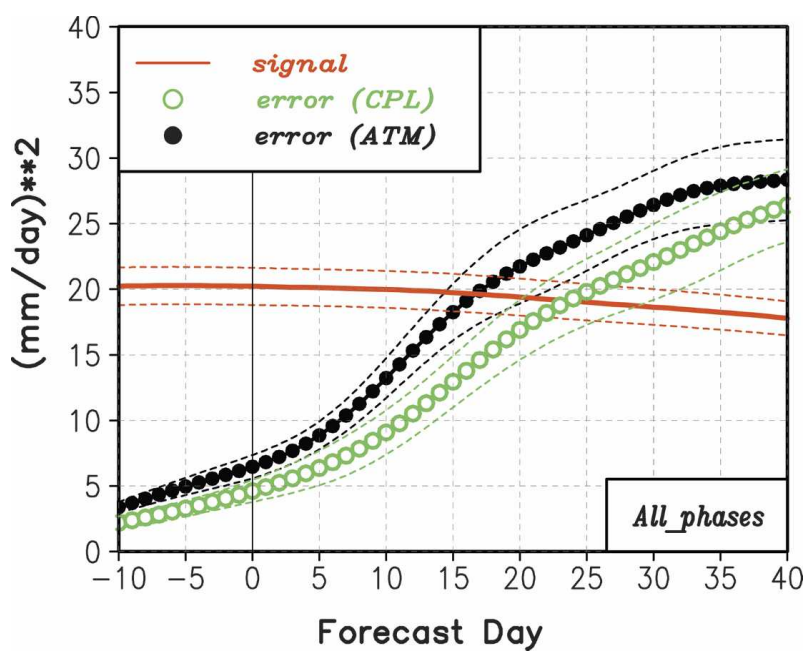

FIG. 6. Same as Fig. 5 except averaged in the Asian-western Pacific region $\left(10^{\circ} \mathrm{S}-30^{\circ} \mathrm{N}, 60^{\circ}-160^{\circ} \mathrm{E}\right)$ for all four phases.

to the signals. At day 30 (Figs. 7e,j), the errors grow beyond the signals over most of the western Pacific region. However, in the eastern Indian Ocean the signals are still significantly larger than the forecast errors.

In Figs. 5 and 6, we have assessed the domain-mean MISO predictability and summarized the overall impact of air-sea coupling. As implied from the spatial inhomogeneity of the signals and forecast errors in the Asian-western Pacific region (Fig. 7), the MISO predictability also shows considerably inhomogeneous distributions in the above area (Fig. 8). If the forecasts start from phase 1 , the predictability is longer than 25 days in the Southeast Asia around $15^{\circ} \mathrm{N}$, equatorial western Indian Ocean, the WNP, and southern Maritime Continent (Fig. 8a). Referring back to the rainfall anomaly pattern at the initial state (Fig. 4a), the positive rainfall region around $15^{\circ} \mathrm{N}$ has relatively longer predictability compared to the dry zone in the eastern Indian Ocean. When started from phase 2 (Fig. 4b), a large area from the equatorial Indian Ocean to the Maritime Continent has predictability longer than 25 days (Fig. 8b). It suggests that once an active phase is initiated in the western equatorial Indian Ocean with significant positive SST anomaly presenting in the central-eastern Indian Ocean (Fig. 4b), the eastward propagation of the MISO is well predictable in this hybrid coupled model. If started from phase 3 , the most predictable region is also in the equatorial Indian Ocean and Maritime Continent (Fig. 8c) primarily associated with positive rainfall anomalies (Fig. 4c). Started from phase 4, the areas with predictability longer than 25 days are relatively scattered (Fig. 8d). The above results tend to suggest that the predictability is longer when the forecasts are started from active phase than that started from break phase. This is consistent with what was found in Figs. 5a,c.

Figure 9 shows the averaged predictability for all four phases (Fig. 8) in the coupled model and its differences with the atmosphere-only model in the tropical Asianwestern Pacific region. In the coupled model (Fig. 9a), the area with mean predictability longer than 25 days is primarily confined in the Indian sector and Maritime Continent. The predictability in the western Pacific is relatively lower with a value of about 20 days. The relatively low predictability in the WNP is likely due to two things: (i) the signals are underestimated in the WNP and (ii) the errors grow relatively faster there (Fig. 7). The area of highest predictability (longer than 35 days) is in the eastern equatorial Indian Ocean. Airsea coupling improves the MISO predictability over almost the entire Asian-western Pacific region (Fig. 9b), particularly in the northeast Indian Ocean and the WNP. The maximum extension of the MISO predictability by air-sea coupling reaches about 15 days in the eastern Indian Ocean.

\section{b. MISO predictability measured by anomaly correlation coefficient}

As demonstrated in previous studies (e.g., Hollingsworth et al. 1980; Waliser et al. 2003b,c), the ratio of signal-to-error is a useful measure of synoptic weather and ISO predictability. On the other hand, this method also bears some uncertainties: for example, the way to define the signal. To assess the uncertainties to some degree, an alternative approach for quantifying MISO predictability is also used. In the following analysis, the anonymous correlation coefficient (Miyakota et al. $1972)$ is calculated in the AWP region $\left(10^{\circ} \mathrm{S}-30^{\circ} \mathrm{N}, 60^{\circ}-\right.$ $\left.160^{\circ} \mathrm{E}\right)$. It is the same area used to define the domainmean signals and errors in Fig. 6.

Figure 10 shows the averaged ACC of all selected events at individual phases and four-phase mean for both the coupled forecasts and atmosphere-only forecasts. One common feature at all phases is that the ACC of the coupled model is systematically larger than that of the atmosphere-only model. If the forecast skill is measured as the day when the ACC drops to 0.5 as defined before, the resultant MISO predictability is very similar with that measured by signal-to-error ratio (Fig. 6). The mean MISO predictability averaged for all phases (Fig. 10e) is about 22 days in the coupled model and about 17 days in the atmosphere-only model. This result further confirms that the coupled model could better track the space-time evolutions of the selected MISO events in the AWP region compared to the atmosphere-only model. 
Signal
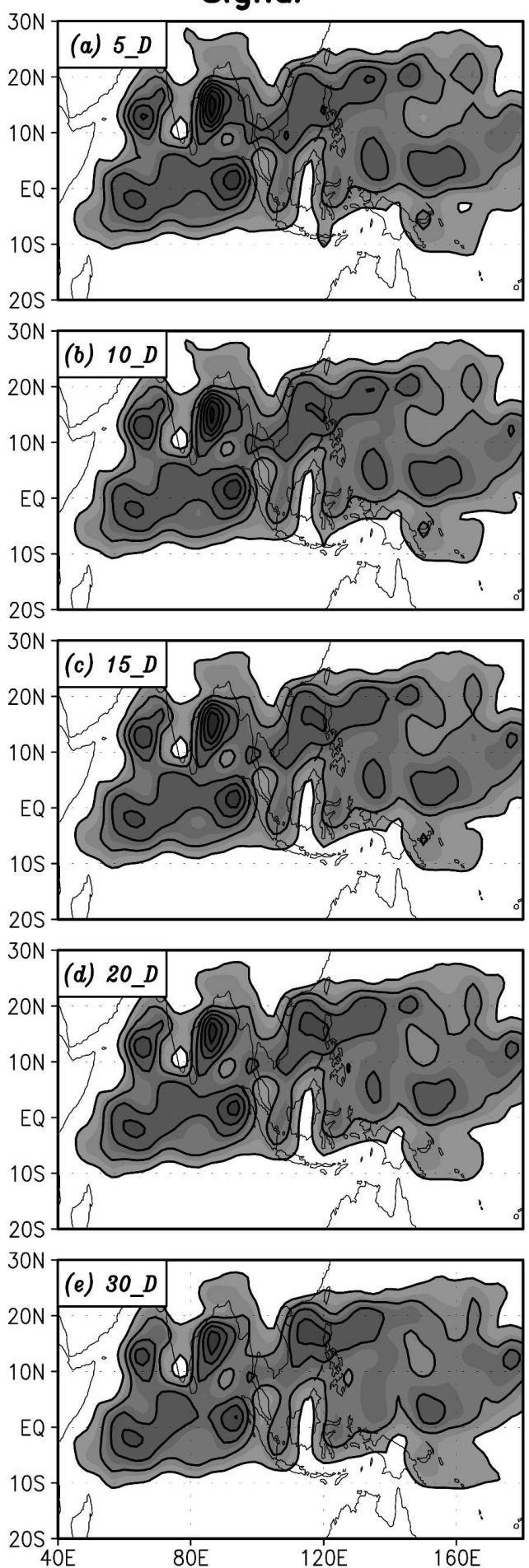

Error
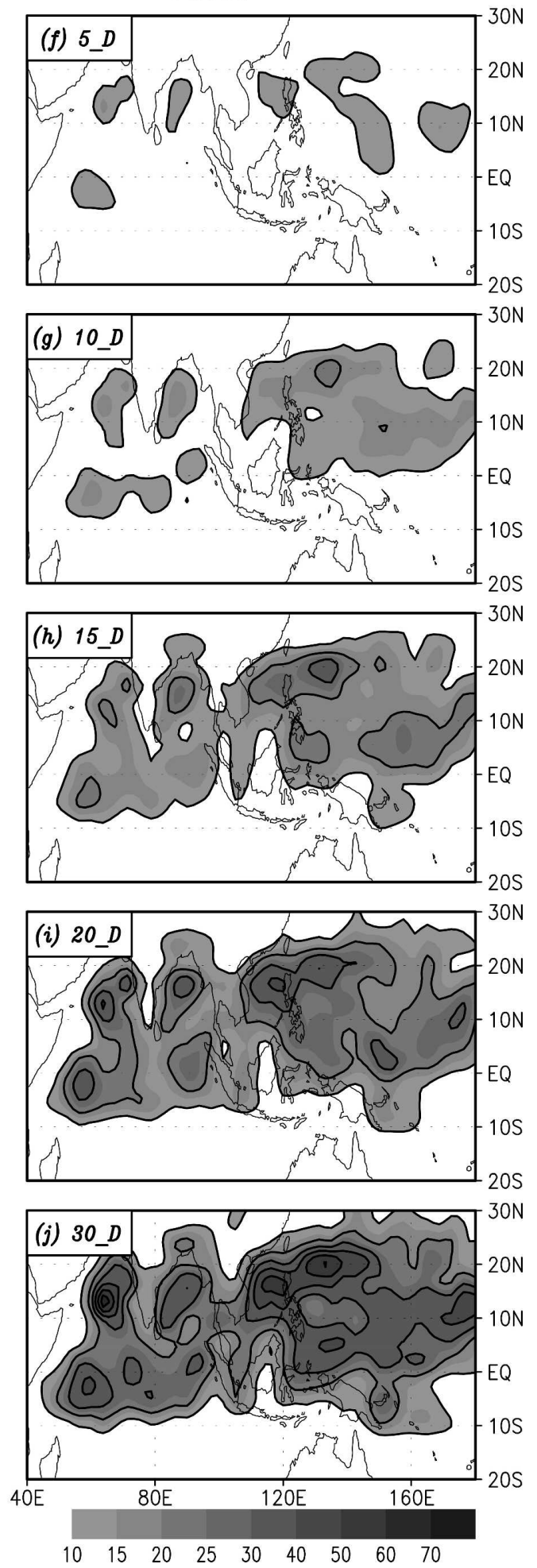

FIG. 7. The spatial distributions of rainfall signals and forecast errors $\left(\mathrm{mm} \mathrm{day}^{-1}\right)^{2}$ in the coupled model at lead times of (a), (f) 5 days; (b), (g) 10 days; (c), (h) 15 days; (d), (i) 20 days; and (e), (j) 30 days. 

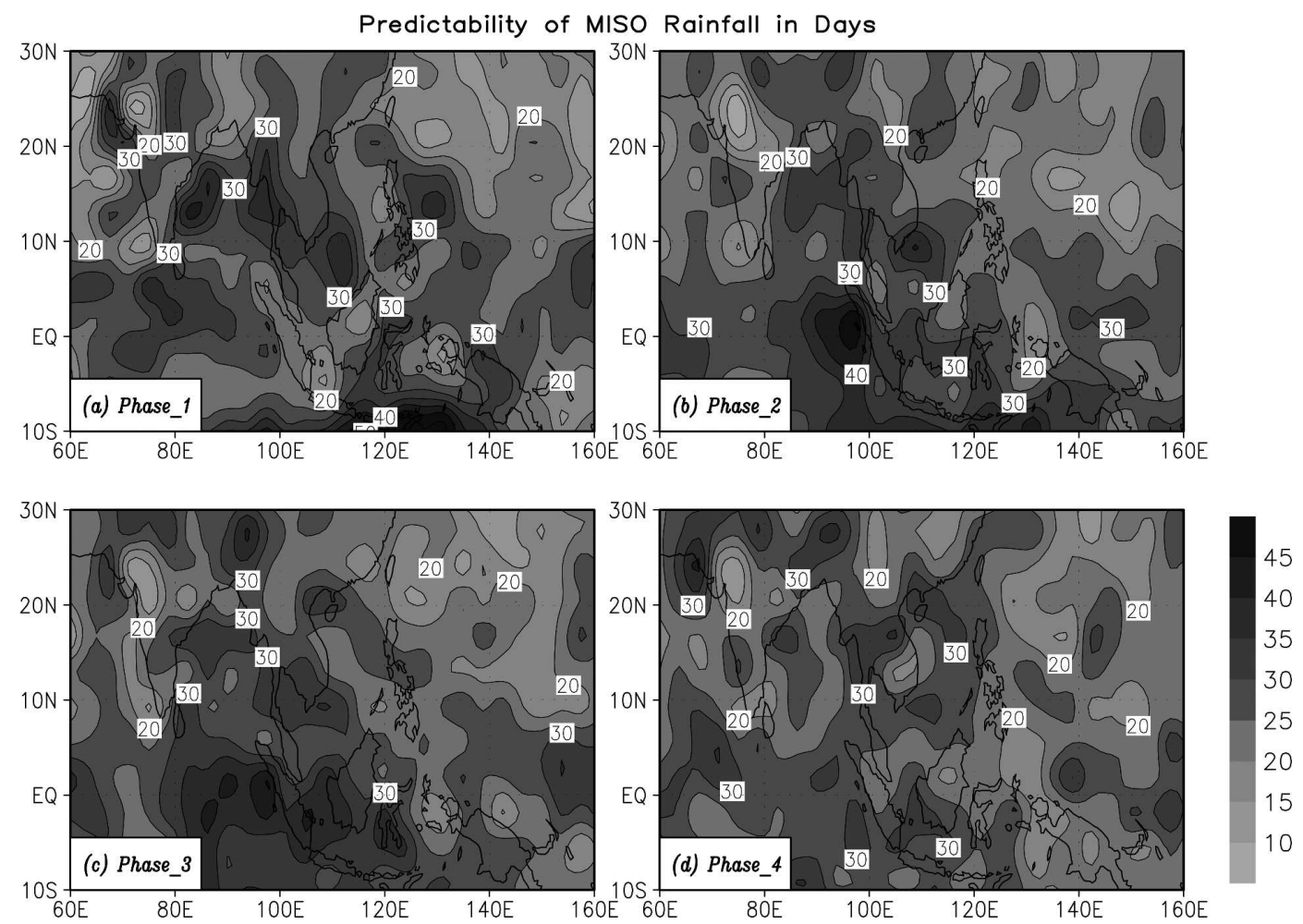

FIG. 8. The spatial distributions of the MISO-related rainfall predictability in days for the coupled model as forecasts start from (a) phase 1, (b) phase 2, (c) phase 3, and (d) phase 4.

\section{Dependence of MISO predictability on active and break phases}

Goswami and Xavier (2003) have estimated the socalled intrinsic predictability of the MISO from the time series of 23-yr observed rainfall intraseasonal variations in the Indian subcontinent. Through quantifying the spreads of the MISO evolutions started from the active phase and break phase, they suggested that the predictability is longer when forecasts started from the active phase than from the break phase. Because the active (break) phase usually will evolve into break (active) phase, Goswami and Xavier also suggested that the monsoon break phase is more predictable than the monsoon active phase. Waliser et al. (2003b,c) and Seo et al. (2005), respectively, have used NASA GLA and NCEP AGCMs to reach very similar conclusion for both the MISO and MJO as Goswami and Xavier revealed from the observations. In this section, we are going to examine the dependence of the MISO predictability on the initial atmospheric conditions and final atmospheric states in both the atmosphere-only and coupled models.

First, the signal-to-error ratio of individual forecast on each grid point over the AWP region $\left(10^{\circ} \mathrm{S}-30^{\circ} \mathrm{N}\right.$, $60^{\circ}-160^{\circ} \mathrm{E}$ ) was binned as functions of initial rainfall anomalies and forecast days. Therefore, any dependence of the MISO predictability on geographic location and phase has been averaged out. The results from the coupled model and atmosphere-only model are shown in Figs. 11a,b. In both systems, the signal-toerror ratio is larger when the forecasts started from active phase than that from break phase. This is consistent with what implied in previous figures (e.g., Figs. 5 and 8 ). The minimum predictability occurs when forecasts start from transition phase (with rainfall anomalies near zero). To explore the possible impact of airsea coupling on predictability dependence, the results from the coupled system (Fig. 11a) have been redrawn as contours onto the results of the atmosphere-only system (Fig. 11b). It turns out that air-sea coupling tends to extend the MISO predictability uniformly regardless the starting phases of the forecasts.

Figure 12 shows an analogous diagram but binned as functions of forecast days and final atmospheric states (represented by rainfall anomalies). Apparently, break phase is more predictable than active phase in both the coupled system and atmosphere-only system. This is consistent with what found by Waliser et al. (2003b,c) and Goswami and Xavier (2003). For extreme dry cases 

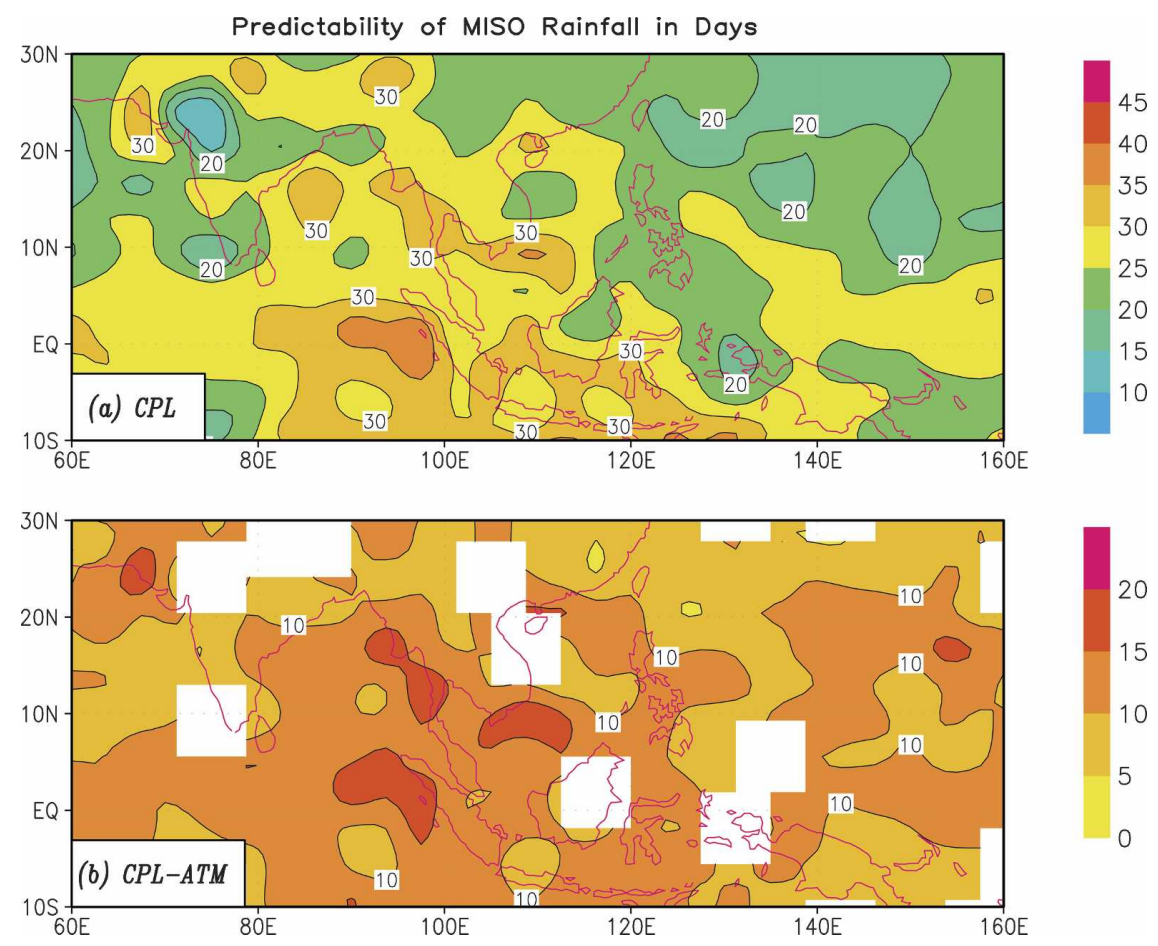

FIG. 9. The spatial distributions of the MISO-related rainfall predictability in days averaged for all four phases (a) from the CPL, and (b) the difference (only the region with significance higher than $95 \%$ is shown) between the coupled model and the atmosphere-only model (CPL-ATM). The contour interval is (a) 10 days and (b) 5 days.

(e.g., rainfall anomaly as $-6 \mathrm{~mm} \mathrm{day}^{-1}$ ), even at 35 days, the averaged signals are still larger than the averaged forecast errors. For extreme wet phase (with rainfall anomaly as $\left.+6 \mathrm{~mm} \mathrm{day}{ }^{-1}\right)$, the averaged predictability is only about 20 days (Fig. 12a). As illustrated in Fig. 11b, Fig. 12b further demonstrates that air-sea coupling almost uniformly extends the MISO predictability of the atmosphere-only model.

The above results suggest that, after averaging out the dependences on geographic location and phase, the MISO predictability shows distinctive asymmetry for active phase and break phase in both the atmosphereonly model and coupled model. If forecasts start from active phase, the predictability is relatively higher (Fig. 11). Because active phase usually evolves into break phase, this is consistent with the result presented in Fig. 12 in which break phase is more predictable than active phase.

\section{Discussions}

The main objective of this study is to assess possible impact of air-sea coupling on the MISO predictability. The results presented in previous sections have demonstrated that including an interactive ocean signifi- cantly improves the MISO predictability of an atmosphere-only model. However, a few interesting questions emerged, for example: 1) Why does air-sea coupling improve the MISO predictability? 2) Why is the MISO predictability higher for break phase than for active phase? A brief discussion of these questions is given here in order to stimulate future in-depth research.

\section{a. Why does air-sea coupling improve the MISO predictability?}

In our previous studies (Fu et al. 2003; Fu and Wang 2004a,b), we have shown that this hybrid coupled model produces much more realistic MISO simulation (e.g., the intensity of the propagating modes and the rainfall-SST relationship) compared to the atmosphere-only model. The better simulation is due to the coupled model capturing the two-way interactions between the MISO and underlying ocean, which most likely operate in the real world (Stephens et al. 2004). The surface heat flux anomalies associated with MISO convection produce positive SST anomalies in its propagating direction (Shinoda et al. 1998; Sengupta and Ravichandran 2001; Fu et al. 2003). These positive SST anomalies warm up and moisten the atmospheric 
Anomaly Corr. Coeff. for MISO Rainfall

(a) Phase 1

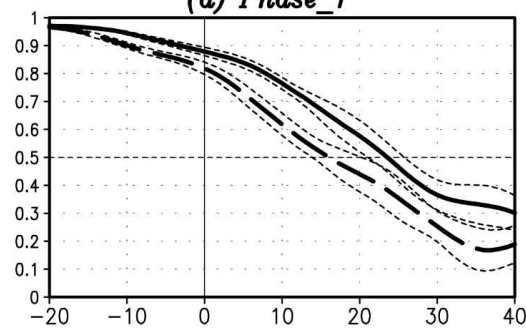

(c) Phase 3

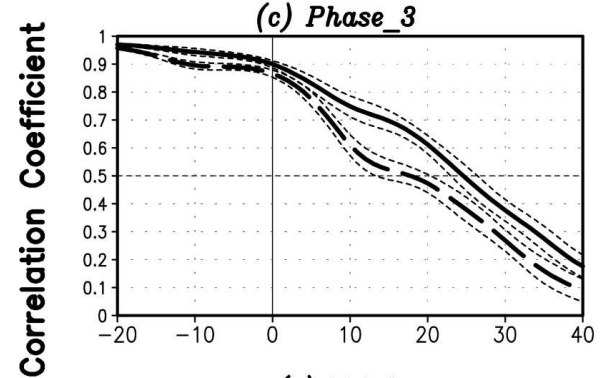

(e) Total

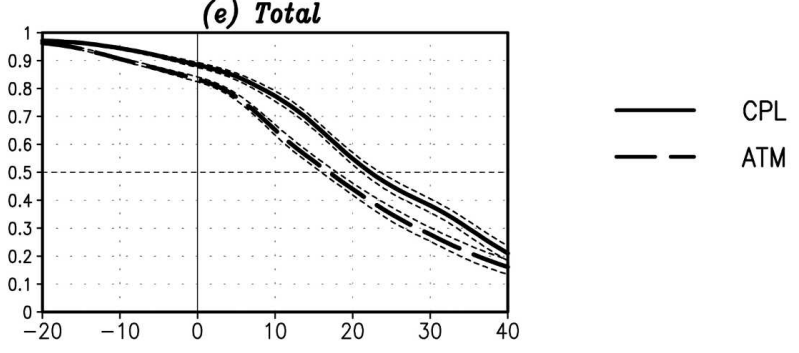

(b) Phase 2

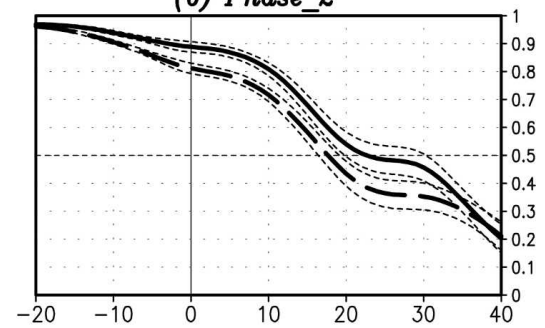

(d) Phase_4

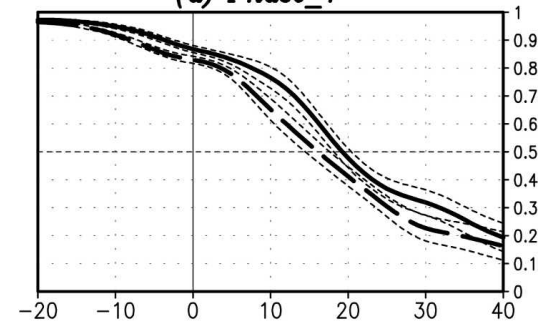

CPL

Forecast Day

FIG. 10. The MISO-related rainfall predictability as measured by ACC over the Asianwestern Pacific region $\left(10^{\circ} \mathrm{S}-30^{\circ} \mathrm{N}, 60^{\circ}-160^{\circ} \mathrm{E}\right)$ when forecasts start from (a) phase 1 , (b) phase 2, (c) phase 3, (d) phase 4, and (e) all four phases with the CPL and ATM. The thin dotted lines give the $95 \%$ confidence limits for the respective variables using a Students $t$ test.

boundary layer (Lau and Sui 1997; Fu et al. 2003, 2006), thus destabilizing the troposphere and providing an external forcing to the MISO evolutions and propagations. In this predictability study, the initial conditions (both the mean states and MISO signals) are the same for both the coupled experiments and atmosphere-only experiments. As mentioned before, in the coupled forecasts both the internal atmospheric dynamics and underlying SST anomalies work together to govern the evolutions and propagations of the MISO. While in the atmosphere-only forecasts, the MISO evolutions are only governed by internal atmospheric dynamics (Lau and Chan 1986; Wang 1988; Jiang et al. 2004). The additional external forcing offered by intraseasonal SST anomalies in the coupled model is the key factor to extend the MISO predictability of an atmosphere-only model.

\section{b. Why is the MISO predictability higher for break phase than for active phase?}

Figures 5a,c give a hint about the possible reason. The forecasts in Fig. 5a (Fig. 5c), respectively, represent the break-to-active (active-to-break) evolutions of the MISO in the EIO. The forecast errors grow much faster during break-to-active transition (Fig. 5a) than during active-to-break transition (Fig. 5c), which is particularly clear for the atmosphere-only forecasts. The different behaviors of error growth in these two periods may be related to the different processes controlling these transitions (Goswami and Xavier 2003; Waliser et al. $2003 b, c)$. The transition from break to active is governed by fast-growing convective instability. On the other hand, the transition from active to break is governed by the large-scale overturning circulation (Gos- 
Predictability Ratio (signal/error) vs. Initial Rainfall
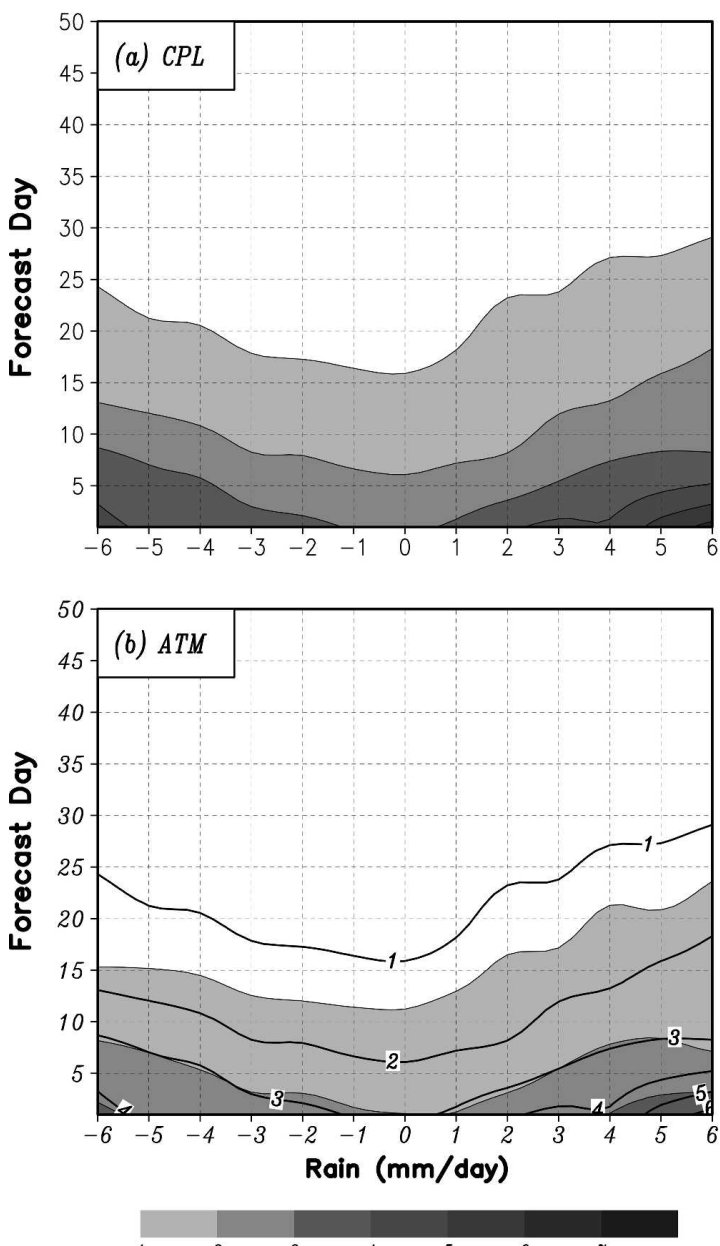

FIG. 11. Predictability ratio of signal-to-forecast errors binned as functions of initial rainfall anomalies and forecast days over the Asian-western Pacific region $\left(10^{\circ} \mathrm{S}-30^{\circ} \mathrm{N}, 60^{\circ}-160^{\circ} \mathrm{E}\right)$ for (a) the CPL and (b) the ATM. The area with predictability ratio larger than one is shaded. The results from the coupled model (a) have been redrawn on (b) as contours.

wami and Xavier 2003). When a small perturbation is introduced in the break phase (Fig. 5a), it grows slowly first but rapidly later when convective instability becomes active. If a small perturbation is introduced in the active phase (Fig. 5c), it grows fast initially but becomes flattened later. Different error growth regimes during these two transition periods result in the break phase being more predictable than the active phase.

\section{Conclusions}

Many previous studies have shown that air-sea coupling can improve the simulations of tropical intraseasonal oscillations in one-way or the other (Flatau et al.
Predictability Ratio (signal/error) vs. Rainfall
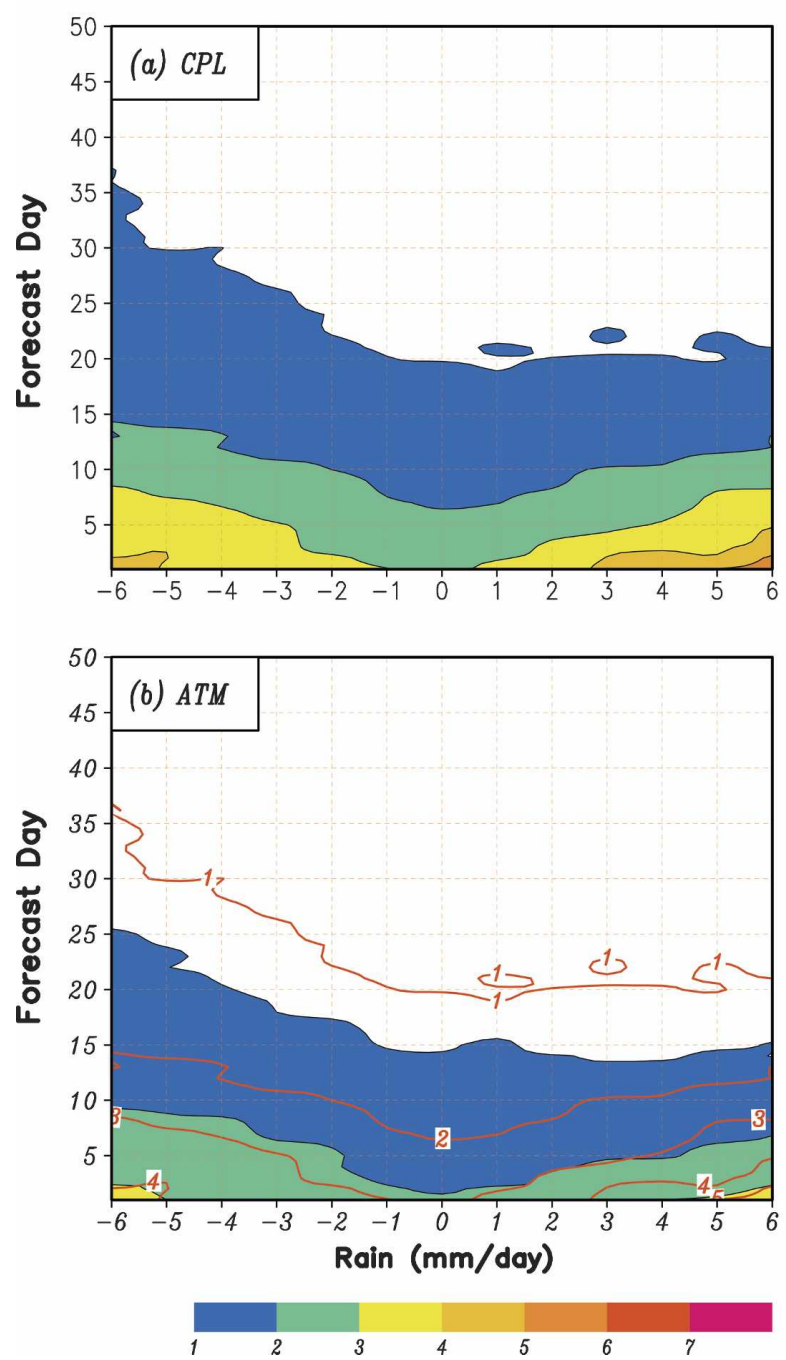

FIG. 12. Same as Fig. 11 but binned as functions of final rainfall anomalies and forecast days.

1997; Waliser et al. 1999b; Kemball-Cook et al. 2002; Fu et al., 2003; Inness and Slingo 2003; A. G. Marshall and O. Alves 2006, personal communication; and among others). In this study, we extended previous work to assess in what degree air-sea coupling can impact the predictability of Monsoon Intraseasonal Oscillations (MISO). Our results indicate that including an interactive ocean significantly extends the MISO predictability of an atmosphere-only model (Figs. 5, 6, 9, 10). The break phase of the MISO has much higher predictability than the active phase in both the atmosphere-only and coupled models. The possible reasons have been discussed in the above section.

In this study, a hybrid atmosphere-ocean coupled model is used (Fu and Wang 2004b; X. Fu et al. 2006, 
unpublished manuscript). It reasonably simulates the major observed characteristics of the MISO over the Asian-western Pacific region, particularly in the Indian sector (Fig. 1, see also the validations in Fu et al. 2003; Fu and Wang 2004b; X. Fu et al. 2006, unpublished manuscript). To assess the model predictability of the MISO, 20 intraseasonal events during boreal summer have been selected from a 15-yr control run (Fig. 2). Four phases (i.e., break, break-to-active, active, and active-to-break) are defined for individual MISO events based on the rainfall time series at the eastern Indian Ocean $\left(5^{\circ} \mathrm{S}-5^{\circ} \mathrm{N}, 80^{\circ}-100^{\circ} \mathrm{E}\right)$. A series of twin perturbation forecasts have been conducted for each phase of all selected MISO events using both the coupled model and the atmosphere-only model. Two complementary measures are used to quantify the MISO predictability: (i) the ratio of signal-to-forecast error, and (ii) the spatial anomaly correlation coefficient (ACC).

When measured with the ratio of signal-to-forecast error, the predictability in the tropical Indian sector is generally higher than that in the western North Pacific (Fig. 9a). The relatively lower predictability in the WNP is probably due to two reasons. First, the MISO variability (i.e., the signal) in this region is underestimated (Figs. 7a-e). Second, the forecast errors tend to grow faster in the WNP (Figs. 7f-j) probably owing to the intrinsic instability (Lau and Lau 1990). Air-sea coupling extends the MISO predictability almost over the entire Asian-western Pacific domain (Fig. 9b). Averaged over this area $\left(10^{\circ} \mathrm{S}-30^{\circ} \mathrm{N}, 60^{\circ}-160^{\circ} \mathrm{E}\right)$, the predictability of the MISO-related rainfall reaches about 24 days in the coupled model and is about 17 days in the atmosphere-only model (Fig. 6). Very similar conclusion was obtained when measured with the anomaly correlation coefficient (Fig. 10). These results suggest that air-sea coupling is able to extend the predictability of the MISO-related rainfall by about a week in its most active domain.

The predictability of the MISO is phase dependent in both the atmosphere-only model and the coupled model (Figs. 11, 12). The predictability is higher when forecasts start from active phase than that from break phase (Fig. 11), the result of which is that the break phase of the MISO is more predictable than the active phase (Fig. 12). This is consistent with what found from previous observational and modeling studies (Goswami and Xavier 2003; Waliser et al. 2003a,b). Air-sea coupling almost uniformly extends the predictability of the MISO for all phases (Figs. 11b, 12b).

Because both the coupled forecasts and atmosphereonly forecasts have same initial conditions, the extension of MISO predictability in the coupled case can only come from the intraseasonal SST anomalies, which have been removed from the atmosphere-only forecasts. The almost uniform enhancement of MISO predictability by air-sea coupling (Figs. 11b, 12b) suggests that both the positive and negative intraseasonal SST anomalies play equally important role. The positive SST anomalies destabilize the atmosphere ahead of the convection. At the same time, the negative SST anomalies stabilize the atmosphere below the convection. Both processes help the MISO-related convection propagate northeastward.

In this study, we only assessed the impact of air-sea coupling on the MISO predictability in boreal summer. Further experiments could be conducted to estimate the impact of air-sea coupling on the MJO predictability in boreal winter. Most experiments we have done in current study consider only two scenarios: fully atmosphere-ocean coupled model and atmosphere-only model forced with smoothed SST. To thoroughly understand the impacts of underlying boundary conditions on the MISO predictability, a few more sensitivity experiments should be conducted: for example, using daily SST or damped persistent SST to force the atmospheric model and introducing a simple oceanic mixed layer into the atmospheric model. Our future research will address these issues.

Acknowledgments. This work was supported by NASA Earth Science Program (NNG04GL65G), by NSF Climate Dynamics Program (ATM03-29531), and by the Japan Agency for Marine-Earth Science and Technology (JAMSTEC) through its sponsorship of the IPRC. The third author was supported by the Human Resources Development Fund at the Jet Propulsion Laboratory (JPL), as well as the NSF (ATM-0094416), and the National Atmospheric and Aeronautics Administration (NAG5- 11033). The research at JPL, California Institute of Technology was performed under contracts with the NASA. Comments from two anonymous reviewers greatly help improve the manuscript.

\section{REFERENCES}

Arakawa, O., and A. Kitoh, 2004: Comparison of local precipitation-SST relationship between the observation and a reanalysis dataset. Geophys. Res. Lett., 31, L12206, doi:10.1029/ 2004 GL020283.

Chen, T.-C., and J. C. Alpert, 1990: Systematic errors in the annual and intraseasonal variations of the planetary-scale divergent circulation in NMC medium-range forecasts. Mon. Wea. Rev., 118, 2607-2623.

Dumenil, L., and E. Todini, 1992: A rainfall-runoff scheme for use in the Hamburg climate model. Advances in Theoretical Hydrology, A Tribute to James Dooge, European Geophysical Society Series on Hydrological Sciences, Vol. 1, Elsevier Press, 129-157. 
Flatau, M., P. Flatau, P. Phoebus, and P. Niller, 1997: The feedback between equatorial convection and local radiative and evaporative processes: The implications for intraseasonal oscillations. J. Atmos. Sci., 54, 2373-2386.

Fu, X., and B. Wang, 2001: A coupled modeling study of the seasonal cycle of the Pacific cold tongue. Part I: Simulation and sensitivity experiments. J. Climate, 14, 765-779.

— sonal oscillations simulated in an atmosphere-ocean coupled model and an atmosphere-only model. J. Climate, 17, 12631271.

_ and - 2004b: The boreal-summer intraseasonal oscillations simulated in a hybrid coupled atmosphere-ocean model. Mon. Wea. Rev., 132, 2628-2649.

,,-- T. Li, and J. P. McCreary, 2003: Coupling between northward-propagating, intraseasonal oscillations and sea surface temperature in the Indian Ocean. J. Atmos. Sci., 60, $1733-1753$.

— - , and L. Tao, 2006: Satellite data reveal the 3-D moisture structure of Tropical Intraseasonal Oscillation and its coupling with underlying ocean. Geophys. Res. Lett., 33, L03705, doi:10.1029/2005GL025074.

Gadgil, S., and P. R. S. Rao, 2000: Famine strategies for a variable climate-A challenge. Curr. Sci., 78, 1203-1215.

Gaspar, P., 1988: Modeling the seasonal cycle of the upper ocean. J. Phys. Oceanogr., 18, 161-180.

Goswami, B. N., and R. S. Ajayamohan, 2001: Intraseasonal oscillations and interannual variability of the Indian summer monsoon. J. Climate, 14, 1180-1198.

— , and P. K. Xavier, 2003: Potential predictability and extended range prediction of Indian summer monsoon breaks. Geophys. Res. Lett., 30, 1966, doi:10.1029/2003GL017810.

— , R. S. Ajayamohan, P. K. Xavier, and D. Sengupta, 2003: Clustering of low pressure systems during the Indian summer monsoon by intraseasonal oscillations. Geophys. Res. Lett., 30, 1431, doi:10.1029/2002GL016734.

Hendon, H. H., 2000: Impact of air-sea coupling on the MaddenJulian oscillation in a general circulation model. J. Atmos. Sci., 57, 3939-3952.

— B. Liebmann, M. Newman, J. D. Glick, and J. E. Schemm, 2000: Medium-range forecast errors associated with active episodes of the Madden-Julian oscillation. Mon. Wea. Rev., 128, 69-86.

Hollingsworth, A., K. Arpe, M. Tiedtke, M. Capaldo, and H. Savijarvi, 1980: The performance of a medium-range forecast model in winter-Impact of physical parameterizations. Mon. Wea. Rev., 108, 1736-1773.

IFRC, 2000: World Disaster Report: Focus on Recovery. IFRC, 392 pp.

Inness, P. M., and J. M. Slingo, 2003: Simulation of the MaddenJulian oscillation in a coupled general circulation model. Part I: Comparison with observations and an atmosphere-only GCM. J. Climate, 16, 345-364.

Jiang, X., T. Li, and B. Wang, 2004: Structures and mechanisms of the northward propagating boreal summer intraseasonal oscillations. J. Climate, 17, 1022-1039.

Jones, C., D. E. Waliser, J.-K. E. Schemm, and W. K. M. Lau, 2000: Prediction skill of the Madden and Julian Oscillation in dynamical extended range forecasts. Climate Dyn., 16, 273289.

- - K. M. Lau, and W. Stern, 2004: Global occurrences of extreme precipitation events and the Madden-Julian oscilla- tion: Observations and predictability. J. Climate, 17, 45754589.

Kalnay, E., 2003: Atmospheric Modeling, Data Assimilation and Predictability. Cambridge University Press, 341 pp.

Kemball-Cook, S., B. Wang, and X. Fu, 2002: Simulation of the ISO in the ECHAM4 model: The impact of coupling with an ocean model. J. Atmos. Sci., 59, 1433-1453.

Krishnamurti, T. N., M. Subramaniam, D. K. Oosterhof, and G. Daughenbaugh, 1990: Predictability of low-frequency modes. Meteor. Atmos. Phys., 44, 63-83.

— — - G. Daughenbaugh, D. Oosterhof, and J. H. Xue, 1992: One-month forecasts of wet and dry spells of the monsoon. Mon. Wea. Rev., 120, 1191-1223.

Lau, K. H., and N. C. Lau, 1990: Observed structure and propagation characteristics of tropical summertime synoptic scale disturbances. Mon. Wea. Rev., 118, 1888-1913.

Lau, K. M., and P. H. Chan, 1986: Aspects of the 40-50-day oscillation during the northern summer as inferred from outgoing longwave radiation. Mon. Wea. Rev., 114, 1354-1367.

_ , and F. C. Chang, 1992: Tropical intraseasonal oscillation and its prediction by the NMC operational model. J. Climate, 5, 1365-1378.

_- and C.-H. Sui, 1997: Mechanisms of short-term sea surface temperature regulation: Observations during TOGA COARE. J. Climate, 10, 465-472.

Liess, S., D. E. Waliser, and S. D. Schubert, 2005: Predictability studies of the intraseasonal oscillation in ECHAM5 GCM. $J$. Atmos. Sci., 62, 3320-3336.

Lo, F., and H. H. Hendon, 2000: Empirical extended-range prediction of the Madden-Julian oscillation. Mon. Wea. Rev., 128, 2528-2543.

Lorenz, E. N., 1982: Atmospheric predictability experiments with a large numerical model. Tellus, 34, 505-513.

Matthews, A. J., 2004: Atmospheric response to observed intraseasonal tropical sea surface temperature anomalies. Geophys. Res. Lett., 31, L14107, doi:10.1029/2004GL020474.

Miyakoda, K., G. D. Hembree, R. F. Strickler, and I. Shulman, 1972: Cumulative results of extended forecast experiment. I. Model performance for winter cases. Mon. Wea. Rev., 100, 836-855.

McCreary, J. P., and Z. J. Yu, 1992: Equatorial dynamics in a 2.5-layer model. Progress in Oceanography, Vol. 29, Pergamon, 61-132.

Mo, K. C., 2001: Adaptive filtering and prediction of intraseasonal oscillations. Mon. Wea. Rev., 129, 802-817.

Nordeng, T. E., 1994: Extended versions of the convective parameterization scheme at ECMWF and their impact on the mean and transient activity of the model in the tropics. ECMWF Research Dept. Tech. Memo. 206, European Centre for Medium-Range Weather Forecasts, Reading, United Kingdom, $41 \mathrm{pp}$.

Reichler, T., and J. O. Roads, 2005: Long-range predictability in the tropics. Part II: 30-60-day variability. J. Climate, 18, 634650.

Roeckner, E., and Coauthors, 1996: The atmospheric general circulation model ECHAM-4: Model description and simulation of present-day climate. Tech. Rep., Max-Plank-Institute for Meteorology, Rep. 218, 90 pp.

Sengupta, D., and M. Ravichandran, 2001: Oscillations of Bay of Bengal sea surface temperature during the 1998 summer monsoon. Geophys. Res. Lett., 28, 2033-2036.

Seo, K.-H., J.-K. Schemm, and C. Jones, 2005: Forecast skill of the 
Tropical Intraseasonal Oscillation in the NCEP GFS dynamical extended range forecasts. Climate Dyn., 25, 265-284.

Shinoda, T., H. H. Hendon, and J. Glick, 1998: Intraseasonal variability of surface fluxes and sea surface temperature in the tropical western Pacific and Indian Oceans. J. Climate, 11, 1685-1702.

Stephens, G. L., P. J. Webster, R. H. Johnson, R. Engelen, and T. L'Ecuyer, 2004: Observational evidence for the mutual regulation of the tropical hydrological cycle and tropical sea surface temperatures. J. Climate, 17, 2213-2224.

Tam, C. Y., and T. Li, 2006: The origin and dispersion characteristics of the observed summertime synoptic-scale waves over the western Pacific. Mon. Wea. Rev., 134, 1630-1646.

Taylor, K. E., D. Williamson, and F. Zwiers, 2000: The sea surface temperature and sea-ice concentration boundary condition for AMIP II simulations. PCMDI Rep. 60, Program for Climate Model Diagnosis and Intercomparison, Lawrence Livermore National Laboratory, $25 \mathrm{pp}$.

Tiedtke, M., 1989: A comprehensive mass flux scheme for cumulus parameterization in large-scale models. Mon. Wea. Rev., 117, 1779-1800.

Tracton, M. S., and E. Kalnay, 1993: Ensemble forecasting at NMC: Practical aspects. Wea. Forecasting, 8, 379-398.

Van den Dool, H. M., and S. Saha, 1990: Frequency dependence in forecast skill. Mon. Wea. Rev., 118, 128-137.

Waliser, D. E., K. M. Lau, and J. H. Kim, 1999a: A statistical extended-range tropical forecast model based on the slow evolution of the Madden-Julian oscillation. J. Climate, 12, 19181939.

—,- , and $—$ 1999b: The influence of coupled sea surface temperatures on the Madden-Julian oscillation: A model perturbation experiment. J. Atmos. Sci., 56, 333-358.

, and Coauthors, 2003a: AGCM simulations of intraseasonal variability associated with the Asian summer monsoon. Climate Dyn., 21, 423-446.

_ W. Stern, S. Schubert, and K. M. Lau, 2003b: Dynamic predictability of intraseasonal variability associated with the Asian summer monsoon. Quart. J. Roy. Meteor. Soc., 129, 2897-2925.

, K. M. Lau, W. Stern, and C. Jones, 2003c: Potential predictability of the Madden-Julian oscillation. Bull. Amer. Meteor. Soc., 84, 33-50.

Wang, B., 1988: Dynamics of tropical low-frequency waves: An analysis of the moist Kelvin waves. J. Atmos. Sci., 45, 20512065.

—_, and H. Rui, 1990: Synoptic climatology of transient tropical intraseasonal convection anomalies: 1975-1985. Meteor. Atmos. Phys., 44, 43-61.

— system. Part I: The role of air-sea interaction in maintaining Madden-Julian oscillation. J. Climate, 11, 2116-2135.

— - T. Li, and P. Chang, 1995: An intermediate model of the tropical Pacific Ocean. J. Phys. Oceanogr., 25, 1599-1616.

Webster, P. J., and C. Hoyos, 2004: Forecasting monsoon rainfall and river discharge variability on 15-30-day time scales. Bull. Amer. Meteor. Soc., 85, 1745-1765.

— , V. O. Magana, T. N. Palmer, J. Shukla, R. A. Tomas, M. Yanai, and T. Yasunari, 1998: Monsoons: Processes, predictability, and the prospects for prediction. J. Geophys. Res., $\mathbf{1 0 3}$ (C7) (TOGA special issue), 14 451-14 510.

Yasunari, T., 1980: A quasi-stationary appearance of 30 to 40 day period in the cloudiness fluctuations during the summer monsoon over India. J. Meteor. Soc. Japan, 58, 225-229.

Zheng, Y., D. E. Waliser, W. F. Stern, and C. Jones, 2004: The role of coupled sea surface temperatures in the simulation of the tropical intraseasonal oscillation. J. Climate, 17, 41094134. 